\title{
SER, HISTÓRIA, TÉCNICA E EXTERMÍNIO NA OBRA DE HEIDEGGER ${ }^{1}$
}

\author{
Emmanuel Faye*
}

\begin{abstract}
RESUMO
Com a publicação do curso de 1933 - 1934 que conclama a "exterminação total" do inimigo interior, o ano de 2001 marca uma inflexão na recepção da obra de Heidegger e exige o exame crítico do uso de termos-chave de sua doutrina, tais como o ser, concebido por ele como "termo codificado" (Deckname), a história, a técnica e o extermínio ou aniquilamento (Vernichtung). Trata-se igualmente de recolocar numa perspectiva crítica o projeto mesmo da "obra completa" (Gesamtausgabe).
\end{abstract}

Palavras-chave: Ser. História. Técnica. Extermínio. Heidegger.

\section{RÉSUMÉ}

L'année 2001, avec la publication du cours de 1933-1934 appelant à l' «extermination totale» de l'ennemi intérieur, marque un tournant dans la réception de l'oeuvre de Heidegger, lequel rend nécessaire l'examen critique de l'usage de termes clef de sa doctrine tel que l'être, conçu par lui comme «prête-nom» (Deckname), mais aussi l'histoire, la technique et l'extermination ou anéantissement (Vernichtung). Il s'agit également de remettre en perspective critique le projet même de l' «oeuvre intégrale» (Gesamtausgabe).

Mots-clés: Être. Histoire. Technique. Extermination. Heidegger.

\footnotetext{
* Professor de Filosofia Moderna e Contemporânea na Universidade de Rouen - França. E-mail: emmanuel.faye@gmail.com

1 Tradução para o português de Ana Cristina Armond, Fábio Júlio Fernandes e Francisca Maria Oliveira Linhares.
} 


\section{Introdução}

O ano de 2001, o primeiro de nosso século, marca uma inflexão na publicação da obra de Martin Heidegger. Aquele ano aparecem, com efeito, todos os primeiros cursos professados por ele sob o terceiro Reich. Com o título em aparência nobre de Ser e verdade (Sein und Wahrheit), o duplo volume 36/37 da obra completa (Gesamtausgabe) reúne o curso do semestre de verão de 1933, intitulado A questão fundamental da filosofia (Der Grundfrage der Philosophie), e aquele do semestre de inverno de 1933 - 1934, que tem por título Da essência da verdade (Vom Wesen der Wahrheit). Por que uma inflexão? De um lado, porque estão entre os cursos os mais explicitamente nacional-socialistas e hitlerianos que ele professou: descobre-se que Heidegger não se limita a expor suas teses nacionalsocialistas sobre o ser, a verdade, a historicidade do povo germânico nos discursos políticos, mas as introduz em seus cursos para transmiti-las a seus estudantes sob o manto da "filosofia". De outro lado, porque ele não ensina apenas posições völkisch e racistas inteiramente explícitas, mas, no curso do semestre de inverno de 1933 - 1934, manifesta uma vontade exterminadora.

Esses dois cursos não se permitem facilmente resumir e não se pode deixar de lê-los integralmente. Heidegger mistura duas linguagens: de um lado, para o semestre de verão de 1933, um curso muito escolar, sem dúvida redigido anteriormente, sobre o conceito de metafísica no pensamento moderno, de Descartes a Baumgarten, Kant e Hegel, e, para o semestre de inverno de 1933 - 1934, um curso já pronunciado sobre a caverna de Platão; de outro, o pathos nacional-socialista o mais radical expresso em teses abruptas.

\section{Uma doutrina exterminadora}

Assim, no curso intitulado Da essência da verdade, Heidegger apresenta a seus estudantes como objetivo "esgotar as possibilidades fundamentais da estirpe originalmente germânica e de os conduzir à dominação" [um] die Grundmöglichkeiten des urgermanischen Stammeswesens auszuschöpfen und zur Herrschaft zu bringen (GA 36/37, 
89). Segue uma interpretação radical do "conflito" (polemos) entendido como um "fazer face ao inimigo" (Stehen gegen den Feind), que não é muito devedora de Heráclito, mas deve exagerada e perigosamente a Carl Schimitt. Este último lhe enviara sua edição de 1933 do Conceito do político (Das Begriff des Politischen), adaptada à moda do momento e publicada pela editora nacional-socialista de Hamburgo: Hanseatische Verlagsanstalt. Heidegger lhe havia respondido, em 22 de agosto de 1933, por uma carta de aprovação, na qual anuncia ter pronta há anos uma interpretação nova do polemos heraclitiano. É essa "interpretação" que ele expõe em seu curso:

O combate enquanto fazer face ao inimigo [...]

$\mathrm{O}$ inimigo é aquele, é todo aquele que lança uma ameaça essencial contra a existência do povo e de seus membros. $\mathrm{O}$ inimigo não é necessariamente o inimigo exterior, e o inimigo exterior não é necessariamente o mais perigoso. Pode mesmo parecer que não há inimigo de modo algum. A exigência radical é então encontrar o inimigo, pô-lo em evidência ou talvez mesmo criá-lo, a fim de que tenha lugar o fazer face ao inimigo e que a existência não seja entorpecida.

$\mathrm{O}$ inimigo pode ser inserido na raiz a mais íntima da existência de um povo e se opor à essência própria desse, agir contra ele. Por mais árduo, duro e difícil seja então o combate, uma vez que o afrontamento de uns contra os outros não constitui senão a sua menor parte, frequentemente é uma tarefa bem mais difícil e de mais longo fôlego encontrar o inimigo enquanto tal, pô-lo em evidência, não se deixar iludir por ele, permanecer agressivo, gerir e aumentar sua disponibilidade constante e deflagrar a agressão de longa duração com o objetivo da exterminação total (völligen Vernichtung) ${ }^{2}$.

\footnotetext{
2 « Der Kampf als Stehen gegen den Feind [...]
}

Feind ist derjenige und jeder, von dem eine wesentliche Bedrohung des Daseins des Volkes und seiner Einzelnen ausgeht. Der Feind braucht nicht der äußere zu sein, und der äußere ist nicht einmal immer der gefährlichere. Und es kann so ausstehen, als sei kein Feind da. Dann ist Grunderfordernis, den Feind zu finden, ins Licht zu stellen oder gar erst zu schaffen, damit dieses Stehen gegen den Feind geschehe und das Dasein nicht stumpf werde.

Der Fein kann in der innersten Wurzel des Daseins eines Volkes sich festgesetzt haben und dessen eigenem Wesen sich entgegenstellen und zuwiderhandeln. Um so schärfer 
A insistência com a qual Heidegger preconiza identificar o inimigo interior, até mesmo criá-lo, corresponde bem à nova missão então confiada à Gestapo: a busca do inimigo (die Gegnerforschung) descrita por Viktor Klemperer em seu jornal. Quanto a esse inimigo inserido na raiz a mais íntima do povo germânico, ao qual é preciso saber se opor no longo prazo, tomando por fim sua exterminação completa, ele designa o oponente político à revolução nacional-socialista, mas também, e, sobretudo, o judeu assimilado ao povo alemão, que deve ser identificado como tal a fim se exterminar.

Antes de Heidegger, Ernst Jünger havia, em um texto intitulado Sobre o nacional-socialismo e a questão judaica, dado como única alternativa ao judeu até então assimilado ao povo alemão: "ser ou não ser judeu" (entweder Jude zu sein oder nicht zu sein). Três anos mais tarde, Heidegger vai muito mais longe, pois já não há alternativa: somente "a exterminação total" é tomada por objetivo. Quanto à expressão völligen Vernichtung, é exatamente aquela que emprega a Associação dos estudantes alemães da Universidade de Friburgo, de obediência nazista, em um comunicado publicado em 8 de maio de 1933 pela Breisgauer Zeitung:

A Associação dos estudantes alemães faz o seguinte comunicado: A Associação dos estudantes alemães está decidida a realizar o combate espiritual contra a decomposição judaico-marxista do povo alemão até a exterminação total (völligen Vernichtung). A cerimônia pública de queima dos escritos judaico-marxistas de 10 de maio de 1933 simbolizará esse combate. Alemães, juntai-vos para o combate! Manifestai também publicamente a disposição comunitária ao combate! ${ }^{3}$

und härter und schwerer ist der Kampf, denn dieser besteht ja nur zum geringsten Teil im Gegeneinanderschlagen, oft weit schwieriger und langwieriger ist es, den Feind als solchen zu erspähen, ihn zur Entfaltung zu bringen, ihm gegenüber sich nichts vorzumachen sich angriffsfertig zu halten, die ständige Bereitschaft zu pflegen und zu steigern und den Angriff auf weite Sicht mit dem Ziel des völligen Vernichtung auszusetzen.» Martin Heidegger, Gesamtausgabe, Volume 36/37, Sein und Wahrheit. 1. Die Grundfrage der Philosophie. 2. Vom Wesen der Wahrheit, Frankfurt am Main, Klostermann, 2001, éd. por Hartmut Tietjen, [GA 36/37], 90-91.

3 « Die Studentenschaft der Universität Freiburg erläßt folgenden Aufruf: « Die deutsche Studentenschaft ist entschlossen, den geistigen Kampf gegen die jüdisch-marxistische 
O que constitui a assustadora responsabilidade do professor Heidegger é sua vontade de dar aos apelos à exterminação dos judeus alemães e dos opositores políticos uma aparência de legitimidade e de nobreza existencial e "filosóficas". Ao utilizar os mesmos termos criminosos que a deutsche Studentenschaft nacional-socialista cujos dirigentes lhe são próximos, mostra sem ambiguidade a seus estudantes para qual fim ele aponta.

Todavia, devemos encarar o fato de que se trata de um curso pronunciado em 1933, mas publicado em 2001. Programada por Heidegger após sua morte, a publicação sem nenhuma autocrítica e nenhum remorso de um tal texto me conduz a sustentar que a questão da relação entre Heidegger e o nacional-socialismo compreende em realidade duas questões. A princípio a questão propriamente histórica do comportamento de Heidegger sob a dominação nacional-socialista. Ela diz respeito ao que ele fez, escreveu, ensinou sob o III Reich. Pesquisas inteiramente decisivas foram realizadas com esse propósito. Nos anos de 1980, Hugo Ott provou que a autojustificação de seu reitorado elaborada por Heidegger em 1945 é um texto em que cada frase contém uma omissão ou mentira. Depois dele, Victor Farias mostrou, na terceira parte de seu Heidegger e o Nazismo, que longe de se manter distante do regime após sua demissão da reitoria, Heidegger se engajou em novas ações, mais comprometedoras ainda se isso for possível, como sua participação ativa ao lado de Rosenberg, Schleider e Schmitt da comissão para filosofia do direito da Academia do direito alemão de Hans Franck, encarregada de fundamentar as futuras leis de Nuremberg. É preciso evocar igualmente os trabalhos de Bernd Martin, que mostram a participação ativa de Heidegger na elaboração da nova constituição universitária destinada a introduzir o Führerprinzip na Universidade Alemã, e aqueles de Claudia Schorcht, que descobriu e publicou as reações inquietas dos filósofos da universidade de Munique, quando da convocação de Heidegger, em setembro de 1933, pelo Ministério para ir à referida universidade: eles o julgaram "politicamente muito extremo" (politisch zu

\footnotetext{
Zersetzung des deutschen Volkes bis zur völligen Vernichtung durchzuführen. Als Sinnbild dieses Kampfes gelte die Öffentliche Verbrennung des jüdisch-marxistischen Schriftums am 10. Mai 1933. Deutsche, sammelt euch zu diesem Kampf! Bekundet die Kampfgemeinschaft auch öffentlich. » Breisgauer Zeitung, 8 mai 1933, cité par Schneeberger, Nachlese zu Heidegger. Dokumente zu seinem Leben und Denken. Bern, 1962, p. 30-31.
} 
extrem) e que, com sua "língua extática" (extatischen Sprache) e "com tais frases, os estudantes não podiam ver nenhuma filosofia sendo exposta" ${ }^{4}$. Os arquivos estão longe de ser esgotados, e as pesquisas devem nitidamente prosseguir.

Há, no entanto, outra questão complementar e que se refere mais diretamente à Filosofia. Trata-se de sondar até onde foi a introdução, por Heidegger, de posições radicalmente nacional-socialistas em sua obra. Até qual ponto exatamente, mas também a partir de qual momento e até quando? A questão já não diz respeito somente à filosofia no nacionalsocialismo, mas ao nacional-socialismo na "filosofia", ou antes, no que tem a pretensão de ser tal, pois não penso que possa haver filosofia merecedora desse nome que seja radicalmente racista e exterminadora, como é o ensinamento proferido por Heidegger no curso citado.

\section{O Ser como "termo codificado" (Deckname)}

Parece hoje certo que a questão do nacional-socialismo no pensamento de Heidegger obriga a retomar um tempo bem anterior a 1933. A correspondência com Elfride nos ensina, por exemplo, que ele compra e lê em 1930 o Völkischer Beobachter e que ele se reconhece no ponto de vista do jornal (carta de 2 de outubro de 1930). Quanto a seu antisemitismo radical e seu projeto de dominação essencial da estirpe germânica, encontra-se a expressão a mais explícita desde 1916, antes, então, da revolução bolchevique de 1917 e do tratado de Versalhes de 1918: "A judaização (Verjudung) de nossa cultura e de nossas universidades é com efeito assustador e eu penso que a raça alemã (die deutsche Rasse) deveria encontrar força interior suficiente para chegar ao ápice"s.

Que Heidegger não tenha podido dizer algumas coisas publicamente em 1933 é um fato, mas é significativo que ele precise a

\footnotetext{
4 «mit solchen Phrasen könne den Studenten keine Philosophie geboten werden», Claudia Schorcht, Philosophie an den bayerischen Universitäten 1933-1945, Erlangen, H. Fischer, 1990, p. 237.

5 «Die Verjudung unsrer Kultur u. Universitäten ist allerdings schreckerregend u. ich meine die deutsche Rasse sollte noch soviel innere Kraft aufbringen um in die Höhe zu kommen». Heidegger, "Mein liebes Seelchen!". Briefe Martin Heideggers an seine Frau Elfride 19151970, éd. par Gertrud Heidegger, München, Deutsche Verlags-Anstalt, 2005, p. 51.
} 
Carl Schimitt ter sua interpretação do polemos pronta "há anos". Em um longo texto, publicado em 3 de maio de 1933, no jornal nazista de Friburgo Der Alemanne, afirmou que: "há anos defendeu da maneira a mais eficaz o partido de Adolf Hitler em sua dura luta para o ser e para a potência, sempre esteve pronto ao sacrifício pela santa causa da Alemanha e nunca um nacional-socialista bateu em vão à sua porta"6.

Podemos notar, na frase citada, a expressão "luta para o ser" (Ringen um Sein), e encontraremos mais de uma vez, em Heidegger, o termo "ser" no registro do hitlerismo. Também é necessário a esse propósito se deter sobre a questão que mais contribuiu à sua reputação enquanto "pensador", a saber, a "questão do ser".

Considera-se geralmente que ele teria descoberto um fio condutor filosófico fundamental com sua tematização da diferença ontológica do ser e do ente. Contudo, uma análise atenta de seus escritos prova que se trata muito amplamente de um fio condutor emprestado. Assim, em Ser e tempo, ele se inspira muito literalmente, mas sem nunca o dizer, em seu antigo mestre em Teologia Carl Braig.

Quando no início de Ser e Tempo, Heidegger afirma que "O ser não é derivável pela definição de conceitos superiores, nem representável a partir de conceitos inferiores" escreveu há três décadas em Vom Sein. Abriß der Ontologie: "O ser não é derivável a partir de conceitos superiores e ele não é representável a partir de conceitos inferiores" ". Quanto à diferença entre o ser e o ente, ela figura em uma citação de São Boaventura em evidência na mesma obra de Braig.

Em realidade, a indeterminação radical do ser com respeito a toda determinação conceitual, como de toda existência empírica, é uma

6 «daß er seit Jahren die Partei Adolf Hitlers in ihrem schweren Ringen um Sein und Macht auf wirksamste unterstürtzte, daß er stets bereit war, für Deutschlands heilige Sache Opfer zu bringen, und daß ein Nationalsozialist niemals vergebens bei ihm anpochte. Der Alemanne, Kampfblatt der Nationalsozialisten Oberbadens, cité par G. Schneeberger, op. cit., p. 23.

7 «Das Sein ist definitorisch aus höheren Begriffen nicht abzuleiten und durch niedere nicht darzustellen.» Martin Heidegger, Sein und Zeit, Tübingen, Max Niemeyer, 1927, p. 4.

8 «Aus höhern Begriffen ist der des Seins nicht ableit- und aus niedrigern ist er nicht darstellbar.» Carl Braig, Die Grundzüge der Philosophie. Abriß der Ontologie. Vom Sein, Freiburg im Breisgau, Herder'sch Verlagsbuchhandlung, 1896, p. 22. 
tese tradicional da escolástica [que serve ainda nessa para tentar pensar a relação do criador às criaturas, mas que a ontologia de Braig, amplamente influenciada por Schelling e Hegel que ele ensinou ao jovem Heidegger, desvinculou dessa perspectiva teológica tradicional]. É com uma temível habilidade que Heidegger vai se apoiar sobre essa indeterminação do termo ser para reforçar sua posição feita ao mesmo tempo de domínio, de radicalidade e de recuo. Ele se apropria assim de um ponto de apoio clássico da filosofia: a questão do sentido do ser, desenvolvida notavelmente por Brentano a partir de Aristóteles e da Escolástica e então de forma alguma esquecida, mas, como vamos ver, utilizada para fins radicalmente não filosóficos.

Muito reveladora a esse respeito é uma espantosa carta recentemente descoberta a Kurt Bauch, um amigo íntimo de Heidegger, professor de história da arte da universidade de Friburgo que entrou como ele na NSDAP, em primeiro de maio de 1933. Eis o que Heidegger lhe escreve, em 1 de agosto de 1943: "O que dizes sobre "ser do ente" é exato. É uma fórmula, para mim frequentemente um "termo codificado" (ein Deckname), mas também uma verdadeira crux da filosofia. [...] Por detrás da fórmula, que contém bem uma 'distinção', se esconde alguma coisa de essencial." 9

Efetivamente, com a diferença entre ser e o ente, Heidegger se apropriou de um ponto de apoio da filosofia, mas para se servir como de uma "fórmula" (eine Formel) e mesmo como de um "termo codificado" (ein Deckname) destinado a sugerir uma coisa completamente diferente, que deve permanecer voluntariamente oculta para ser unicamente revelada no momento escolhido. É assim que em certos textos, deixa abruptamente entrever o que quer indicar. A prova, o curso do semestre de inverno de 1934 - 1935 sobre a Germânia de Hölderlin em que exclama, sublinhado no texto editado: "A Pátria é 'o ser' mesmo" (Das Vaterland ist 'das Seyn' selbst). De forma mais explícita ainda, no curso já evocado do semestre de verão de 1933, sobre A questão fundamental da filosofia, resume seu propósito associando entre eles as duas 'questões' seguintes: 1) A filosofia é o perpétuo combate que se pergunta pela essência e o ser do ente e 2) Esta

\footnotetext{
9 «Was du über das 'Sein des Seienden'sagst ist richtig. Es ist eine Formel, für mich oft ein Deckname, aber auch eine wirkliche crux der Philosophie. [...] Hinter der Formel, die ja eine 'Unterscheidung' enthält, verbirgt sich etwas wesentliches. " Martin Heidegger/Kurt Bauch Briefwechsel 1932-1975, Martin Heidegger Briefausgabe, voluume II.1, Verlag Karl Alber, Freiburg/München, 2010, p. 92.
} 
questão é em si histórica, isto é, é a exigência, a discórdia e a veneração de um povo pela dureza e a clareza de sua vontade de destino ${ }^{10}$.

A essência e o ser do ente são, pois, assimilados por Heidegger à dureza e à clareza da vontade de destino do povo germânico. Retenhamos igualmente o acento posto na "historicidade" dessa dupla questão, pois logo veremos o que é histórico em Heidegger.

É preciso evocar também o seminário do semestre de inverno de 1933-1934, intitulado Sobre a essência e os conceitos da natureza, da história e do Estado (Über Wesen und Begriff Von Natur, Geschichte und Staat). Theodore Kisiel havia publicado alguns extratos desse seminário. $\mathrm{Eu}$ editei outros extratos dele e me interroguei publicamente sobre a ausência desse seminário no plano da edição da Gestamtausgabe $e^{11}$. Penso, com efeito, que se Heidegger separou esse seminário da obra integral, é porque nele seu hitlerismo é tão radical e tão explícito que já não pode ter a aparência de uma filosofia. Ele, de fato, tira a máscara e propõe um curso de "educação política" com a finalidade de formar uma "nobreza política" para o III Reich. Ora, nesse curso, destinado claramente a propor uma apologia inteiramente explícita do völkischer Staat e do Führestaat hitleriano, Heidegger quer impor a ideia de que existiria entre o povo e seu Estado uma relação tão essencial e constitutiva quanto entre o ente humano e seu ser próprio. Assim escreve:

Do mesmo modo que o ente, o homem é consciente de seu Ser-homem, se preocupa e cuida disso, assim também o povo-ente mantém uma relação fundamental com seu Estado. O povo, o ente, que em seu Ser

10 «1. Philosophie ist der unausgesetzte fragende Kampf um das Wesen und Sein des Seienden.2. Dieses Fragen ist in sich geschichtlich, d.h. es ist das Fordern, Hadern und Verehren eines Volkes um der Härte und Klarheit seines Schicksals willen.» GA 36/37, 12.

${ }^{11}$ O seminário é agora publicado. Ver: "Über Wesen und Begriff von Natur, Geschichte and Staat. Übung aus dem Wintersemester 1933/34”. In Heidegger und der Nationalsozialismus. Dokumente. Heidegger-Jahrbuch 4, editado por Alfred Denker e Holger Zaborowski, Freiburg/München, Verlag Karl Alber, 2009, p. 53-88.

"So wie das Seiende, der Mensch sich seines mensch-Sein bewusst ist, wie er sich dazu verhält, sich darum kümmert, so hat auch das Seiende Volk ein wissendes Grundverhältnis zu seinem Staat. Das Volk, das Seiende, das in seinem Sein den Staat verwirklicht, weiss um den Staat, kümmert sich um ihn und will ihn. » Martin Heidegger, Über Wesen und Begriff..., p. 76. 
realiza o Estado, tem o conhecimento do Estado, se preocupa com isso e o quer ${ }^{12}$.

A "distinção essencial" que, conforme a futura carta a Kurt Bauch, se esconde segundo Heidegger detrás da "fórmula" ou do "termo codificado" Ser, não é então uma distinção filosófica ou propriamente ontológica, mas aquela, inteiramente política, entre o povo alemão e seu Estado. Essa relação do povo ao Führerstaat é concebida segundo a relação hitleriana entre Führung e Gefolgschaft e segundo o princípio de atração do Männerbund: é o impulso (Drang), é o eros do povo para seu Estado e para seu Führer que Heidegger quer suscitar em seus estudantes.

É preciso de fato ver precisamente que, em realidade, não há política filosófica digna desse nome em Heidegger, pois ele não propõe nenhuma teorização ou conceitualização do Estado e de suas instituições. A palavra Estado em seu discurso é tão indeterminada e vazia quanto o termo Ser. Não há outra função senão dispor os espíritos a se deixarem totalmente possuir e dominar pela vontade do Führer.

Editei em meu livro pela primeira vez a longa conclusão da $7^{\mathrm{a}}$ sessão do seminário na qual, no tom de um tipo de religiosidade nazista, Heidegger expõe como a vontade do Führer penetra no "ser" e na "alma" de seu povo. Eis um extrato dele:

Não é senão aí onde o Führer e aqueles que conduz se ligam em um único destino e lutam pela a realização de uma ideia que pode levar à ordem verdadeira. Então, a superioridade espiritual e a liberdade se realizam enquanto dom profundo de todas as forças do povo, do Estado, enquanto treinamento o mais severo, engajamento, resistência, solidão e amor. Então, a existência e a superioridade do Führer estão encravadas no ser, na alma do povo (eingesenkt in das Sein, in die Seeele des Volkes) e elas o ligam original e apaixonadamente à tarefa. E se o povo sente esse dom, ele se deixará guiar no combate, quererá e

\footnotetext{
12 «So wie das Seiende, der Mensch sich seines mensch-Sein bewusst ist, wie er sich dazu verhält, sich darum kümmert, so hat auch das Seiende Volk ein wissendes Grundverhältnis zu seinem Staat. Das Volk, das Seiende, das in seinem Sein den Staat verwirklicht, weiss um den Staat, kümmert sich um ihn und will ihn. » Martin Heidegger, Über Wesen und Begriff..., p. 76.
} 
amará o combate. Ele desdobrará então suas forças e perseverará, será fiel e se sacrificará. A cada novo instante, o Führer e o povo se ligarão mais estreitamente, a fim de realizar a essência de seu Estado, então de seu ser. Crescendo lado a lado e advertidos, oporão seu ser e seu querer históricos às duas potências ameaçadoras que são a morte e o diabo, quer dizer, a corrupção e a decadência de sua essência autêntica ${ }^{13}$.

Por esse exemplo, vê-se como Heidegger se põe para cativar seus ouvintes. Pródigo na tonalidade de um tipo de religiosidade devotada em que, exatamente como em Mein Kampf, o "diabo" significa na realidade o "judeu", seu ensinamento é animado por uma vontade de dominação total de corações e mentes. Podemos mesmo falar de uma ligação de possessão oculta. Dessa maneira, não se trata de modo algum de um ensinamento filosófico.

\section{A historicidade e a língua Tertii Imperii}

O que acabo de indicar para a palavra Ser e para a palavra Estado vale também para cada uma das palavras-chave do discurso heideggeriano, tais como historicidade ou verdade, por isso quis mostrar precisamente em meu livro como Heidegger utiliza termos da língua filosófica para transmitir uma coisa inteiramente diferente, a saber, os fins mesmos do nacional-socialismo. Carl Schimitt fará o mesmo para a linguagem do direito. Não é possível, pois, nos fixamos nos termos, como o fazem muitos comentadores que se satisfazem com uma interminável paráfrase,

\footnotetext{
13 «Nur wo Führer und Geführte gemeinsam in ein Schicksal sich binden und für die Verwirklichung einer Idee kämpfen, erwächst wahre Ordnung. Dann wirkt sich die geistige Überlegenheit und Freiheit aus als tiefe Hingabe aller Kräfte an das Volk, den Staat, als strengste Zucht, als Einsatz, Standhalten, Einsamkeit und Liebe. Dann ist die Existenz und Überlegenheit des Führers eingesenkt in das Sein, in die Seele des Volkes und bindet es so mit Ursprünglichkeit und Leidenschaft an die Aufgabe. Und wenn das Volk diese Hingabe spürt, wird es sich in den Kampf führen lassen und den Kampf wollen und lieben. Es wird seine Kräfte entfalten und ausharren, treu sein und sich opfern. In jedem neuen Augenblick werden sich Führer und Volk enger verbinden, um das Wesen ihres Staates, also ihres Seins zu erwirken; aneinander wachsend werden sie den beiden bedrohenden Mächten Tod und Teufel, d.h. Vergänglichkeit und Abfall vom eigenen Wesen, ihr sinnvolles, geschichtliches Sein und Wollen entgegensetzen. » Über Wesen und Begriff... 7e séance, § 13, p. 77.
} 
evitando citar as páginas onde as tomadas de posições nacional-socialistas, racistas e exterminadoras o são mais explícitas. Sem dúvida, é às vezes por complacência que se age assim, mas é mais frequentemente a falta de pesquisa fundamental que faz muitos filósofos se deixarem levar por essa linguagem. É preciso, com efeito, uma introspecção que vá bem mais profundamente se se quer discernir exatamente qual é o 'movimento' que anima Heidegger ao longo de seu "caminho". É verdadeiro igualmente que seu modo de escrever, que não compreende verdadeira argumentação, a partir da qual se poderia desenvolver uma discussão crítica, mas consiste em asserções abruptas e ditatoriais, predispõe os espíritos excessivamente escolares e submissos à paráfrase e à repetição.

Após o exemplo do ser, tomemos aquele de historicidade. Esse termo é já central no Ser e tempo, cujo movimento de fundo vai da superação da morte e do "sacrifício de si" (Selbstaufgabe), presentes no $\S$ 53 à afirmação do $\S 74$, segundo a qual o destino histórico do Dasein não advém de modo autêntico senão na comunidade, no povo, quando o Dasein histórico escolhe o seu herói (das Dasein sich seinen Helden wählt) e decide por perseguir o combate ${ }^{14}$. Sobre a significação exata da historicidade da existência, a apresentação já evocada de Heidegger no número 3 de maio de Der Alemanne sublinha sem desviar seu enraizamento völkisch. O texto que se pode nele ler foi de modo muito verossímil revisto e aprovado, até mesmo inspirado pelo reitor Heidegger:

O trabalho filosófico do professor Heidegger é determinado por três traços fundamentais que são longamente expostos e estabelecidos em sua obra maior Ser e tempo. Está em primeiro lugar a doutrina do caráter histórico do Dasein humano. Ele é enraizado na terra, no solo e no ser-povo. O ser do homem se determina a partir de sua resolução para o engajamento no destino ${ }^{15}$.

\footnotetext{
${ }^{14}$ Martin Heidegger, Sein und Zeit, p. 384 et 385, é significativo a este respeito para a primeira antologia de seus escritos publicado em francês em 1938, que Heidegger tenha pedido à Henri Corbin de traduzir os dois capítulos sobre a morte e a historicidade.

15 «Die philosophische Arbeit von Professor H. ist durch drei Grundzüge bestimmt, die in seinem Hauptwerk «Sein und Zeit» eingehend dargestellt und begründet sind. Es ist zunächst die Lehre vom geschichtlichen Charakter des menschlichen Daseins. Es ist in der
} 
Todavia, o $§ 77$ de Ser e Tempo, compilação de citações do conde York, que se refere notadamente à ausência de solo (Bodenlosigkeit), e que constitui o verdadeiro coroamento de Ser e tempo como das conferências de Cassel, pronunciadas dois anos antes, mostra ao leitor avisado em qual espírito antisemita herdado de York são concebidas a historicidade e "a diferença genérica entre ôntico e histórico" ${ }^{16}$. Na correspondência trocada entre York e Dilthey, a ausência de solo é entendida por York em um espírito abertamente antisemita. Eis aqui, com efeito, o que ele escreve a Dilthey, em 18 de fevereiro de 1884:

Eu vos agradeço por todos os casos particulares em que tendes afastado das cátedras do ensino a miserável rotina judaica (die dünne jüdische Routine), à qual falta a consciência da responsabilidade do pensamento, como falta inteiramente à raça (den ganzen Stamme) o sentimento do solo (Boden) psíquico e físico ${ }^{17}$.

Para, em relação a essa questão, retornar ao $§ 77$ de Ser e Tempo, há, de um lado, o Dasein histórico, de outro, aqueles que são sem história. Heidegger exprime isso com palavras dissimuladas em 1927, mas com palavras totalmente explícitas em seu curso do semestre de verão de 1934. Nesse meio tempo, se assiste, nos cursos dos anos de 1933 - 1934, uma potencialização do tema da historicidade. O curso sobre A questão fundamental da filosofia (Der Grundfrage der Philosophie) se inicia pela evocação enfática "da grandeza do momento histórico presente" (der Größe des geschichtlichen Augenblicks), em que "o povo alemão em sua totalidade [...] encontra sua direção" (das deutsche Volk im Ganzen [...] findet seine

Erde, Bodenständigkeit und Volkstum verwurzelt. Das Sein des Menschen bestimmt sich aus seiner Entschlossenheit zum Einsatz in das Schicksal.» (Schneeberger, op. cit., p. 25).

${ }^{16}$ Martin Heidegger, Sein und Zeit, p. 399.

${ }^{17}$ «Ich gratuliere zu jedem einzelnen Fall, wo Sie die dünne jüdische Routine, der das Bewußtsein der Verantwortlichkeit für die Gedanken fehlt, wie dem ganzen Stamme das Gefühl psychischer und physischen Bodens, von der Lehrstühlen fern halten.» Dilthey, Wilhelm, and Paul York v. Wartenburg. Briefwechsel zwischen Wilhelm Dilthey und dem Grafen Paul Yorck v. Wartenburg, 1877-1897, Edited by Sigrist v.d.Schulenburg. Halle, Salle: M. Niemeyer, 1923. p. 254. 
Führung $)^{18}$. O fio condutor desses diferentes cursos é, afirma, a necessidade de uma transformação radical da questão do homem: "é preciso revolucionar a questão do homem. A historicidade é um momento fundamental de seu ser"19. Trata-se de transformar a questão filosófica formulada por Kant: "que é o homem?" (Was ist der Mensch ?) na questão "Quem é o homem?” (Wer is der Mensch? $)^{20}$, ela mesma reformulada como a questão "Quem somos nós?" (Wer sind wir? $)^{21}$. Nesse curso, Heidegger não dá maiores explicações. É no curso seguinte, aquele do semestre de verão de 1934, que as coisas ficarão mais precisas, mas o horizonte da questão "Quem é o homem?" não deixa de ser inquietante. É unicamente pelo fio dessa questão que se pode, segundo ele, haver "alguma coisa como resolução, disponibilidade a servir, combate, dominação" (...so etwas gibt wie Entschlossenheit, Dienstbereintschaft, Kampf, Herrschaft $)^{22}$. Essa retórica nazista toma todo seu sentido em outras passagens do curso, por exemplo, quando evoca "o que advém hoje para nós, para nosso povo" (was mit uns heute geschieht, mit unserm Volk) ${ }^{23} \mathrm{e}$ fala " $d a$ grande transformação da existência do homem" (die große Wandlung des Daseins des Menschen $)^{24}$. O sentido desta "transformação total" é expresso sem ambiguidade:

Quando hoje o Führer fala sem cessar da reeducação em direção da visão do mundo nacional-socialista, isso não significa: inculcar slogan qualquer, mas produzir uma transformação total, um projeto mundial, sobre o fundamento do qual educa todo o povo. O nacional-socialismo não é uma doutrina qualquer, mas a transformação fundamental do mundo alemão e, como nós o cremos, do mundo europeu ${ }^{25}$.

\footnotetext{
${ }^{18}$ GA 36/37, 6.

${ }^{19}$ «die Frage nach dem Menschen muß revolutioniert werden. Die Geschichtlichkeit ist ein Grundmoment seines Seins.» GA 36/37, 215.

${ }^{20}$ Ibid., p. 214.

${ }^{21}$ Ibid., p. 176.

${ }^{22}$ Ibid., p. 215.

${ }^{23}$ Ibid., p. 118.

${ }^{24}$ Ibid., p. 119 (souligné par Heidegger).

${ }^{25}$ «Wenn heute der Führer immer wieder spricht von der Umerziehung zur national-
} 
É preciso se deter no uso heideggeriano do termo verdade (Wahrheit), que dá seu título ao curso. Em realidade, esse termo é perfeitamente intercambiável com o termo história (Geschichte). Com efeito, "a verdade", compreendida já não como exatidão mas como "desvelamento", existe somente "aí onde ela advém como história do homem" (Unverborgenheit [...] ist nur, insofern sie als Geschichte des Menschen geschieht"26.

É então decisivo não cair na armadilha do uso heideggeriano das palavras da língua filosófica. Em seu discurso, se encontra um pequeno número de palavras-chave constantemente repetidas como "essência", "verdade", "liberdade", "história" etc., que não correspondem nem a ideias distintas nem a conceitos determinados, mas são intercambiáveis e funcionam exatamente como esse "jargão da autenticidade" tão bem descrito por Theodor Adorno: o jargão "dispõe de um número módico de palavras que se fecham sobre elas-mesmas e se tornam sinais" ${ }^{27}$. Adorno dá o exemplo da palavra "decisão" (Entscheidung) tão correntemente empregada por Heidegger, tanto em Ser e tempo, quanto em seus cursos dos anos de 1933 - 1935, ou em suas notas de 1940 sobre Ernst Jünger.

No entanto, um autor nos permite ir mais longe ainda na desmistificação crítica de Heidegger: Victor Klemperer. Em sua notável obra LTI - A língua do III Reich, o filólogo observa que entre as três primeiras palavras as mais comprometidas pela linguagem nacionalsocialista, está a palavra "histórico": "histórico é cada encontro do Führer com o Duce, mesmo se ele não muda em nada a situação do momento"23.

Ora, no curso em que Heidegger apresenta a explicação a mais desenvolvida do que ele entende pela palavra "história", a saber, o curso do

sozialistischen Weltanschauung, heißt das nicht: irgendwelche Schlagworte beibringen, sondern einen Gesamtwandel hervorbringen, einen Weltentwurf, aus dessen Grund heraus er das ganze Volk erzieht» GA 36/37, 225.

${ }^{26}$ Ibid.

${ }^{27}$ «Er [der Jargon der Eigentlichkeit] verfügt über eine bescheidene Anzahl signalhaft einschnappende Wörter» Theodro Adorno, Jargon der Eigentlichkeit, Zur deutschen Ideologie, Frankfurt am Main, Suhrkamp, 1964, p. 9.

${ }^{28}$ «historisch ist jede Zusammenkunft des Führers mit den Duce, auch wenn sie gar nicht an den bestehenden Verhältnisse ändert.» Victor Klemperer, LTI - Notizbuch eines Philologen, Leipzig, Reclam, 1974, p. 45. 
semestre de verão de 1934 intitulado Lógica (Logik), após ter sustentado que a historicidade é constitutiva da existência humana, afirma que há, todavia, "homens e grupos de homens" - já nem mesmo diz povos "que não têm história, que são privados de história (os negros como, por exemplo, os Cafres)" (es Menschen u. Menschengruppen (Neger wie z. b. Kaffern) gibt, die Kiene Geschichte haben, sie seien geschichtslos ${ }^{29}$. Ou antes, "eles não têm mais história que os macacos e os pássaros" (Die haben doc ebensogut Geschichte wie die Affen u. Vögel) ${ }^{30}$.

Ao contrário, prossegue o antigo reitor: "Quando o avião conduz o Führer de Munique a Veneza para ver Mussolini, então advém a história"31.

Esses textos são muito reveladores do nível de pensamento de Heidegger. Não provam somente a extensão de seu racismo e de seu hitlerismo, mas correspondem exatamente à descrição irônica de Klemperer. Com efeito, a viagem de Hitler ao encontro de Mussolini, em 14 e 15 de junho de 1934, é um fracasso diplomático completo: Hitler queria obter de Mussolini seu acordo para invadir a Áustria, mas se depara com recusa do Duce. Heidegger não faz menos sua a retórica oca da LTI, repete o que, sem dúvida, pôde ler nos editoriais do Völkicher Beobachter do dia, e acrescenta: com essa viagem do Führer, afirma a seus estudantes, não somente "advém a história" (geschieht Geschichte), mas "mesmo um ente não humano como o avião que serviu para transportar o Führer pode tornar-se histórico" 32 !

Heidegger disfarça, entretanto, esse oportunismo oco e desprovido de pensamento sob a aparência de um tipo de "neo-hegelianismo". À questão: "que é a história?" (Was ist Geschichte?), responde: "o momento presente" (Das Heutige) $)^{33}$. No entanto, não se trata mesmo de um

\footnotetext{
${ }^{29}$ Martin Heidegger, Gesamtausgabe, Volume 38. Logik als die Frage nach dem Wesen der Sprache, éd. por Günther Seubold, Frankfurt am Main, Klostermann, 1998, 81.

${ }^{30}$ Ibid., 84

31 «Wenn das Flugzeug freilich den Führer von München zu Mussolini nach Venedig bringt, dann geschieht Geschichte.» Ibid. "Wenn (...) Geschichte.” Ibid.

32 «auch nicht menschliches Seiendes, wie z.b. das erwähnte Flugzeug des Führers, kann geschichtlich werden.»Ibid., 86.

${ }^{33}$ Ibid., respectivement p. 97 et 99.
} 
reconhecimento da efetividade do presente, qualquer que ele seja. Com efeito, essa posição não é sustentada por ele senão enquanto o curso da história parece favorável ao nacional-socialismo. É assim, que em 1940, afirma que "não devemos querer ultrapassar as zonas de decisão" 34 . Na conclusão do curso do semestre de verão de 1940, oportunamente suprimida no Nietzsche, publicado em 1961, mas restabelecida na Gesamtausgabe, engrandece a motorização da Wehrmacht como "um ato metafísico".

A partir de 1945, ao contrário, repete voluntariosamente que as "guerras mundiais [...] não decidem historicamente destinos" 35 . Na Carta sobre o humanismo, escrita no fim do ano de 1946, quando a nova noção jurídica de crime contra a humanidade é criada por ocasião dos processos de Nuremberg, a historicidade já não é, como em 1933 - 1934, identificada ao presente, ao "atual" (das Heutige), agora que a época lhe é totalmente adversa, nem à "questão fundamental da filosofia" que se referia sobre o ser do povo germânico reunido no Führerstaat. Em 1946, a filosofia sendo doravante recusada por Heidegger, a historicidade é, em sua nova linguagem extática do pós-guerra, relacionada à "história do ser" e ao "pensamento vindouro" (die künftige Denken), que toma por incumbência a tarefa de pensar l'Heimatlosigkeit, a perda da terra natal ou da pátria.

\section{O negacionismo das Conferências de Bremem de 1949}

Heidegger está proibido de ensinar, mas não de proferir conferências nem de publicar, ele tem todo o seu tempo livre para preparar o seu comeback, segundo a palavra cáustica e invejosa empregada a seu propósito por Carl Schmitt em seu Glossarium. Efetivamente, logo que o processo de "desnazificação" terminou - com a classificação, em março de 1949, de Heidegger como simples "simpatizante" (Mitlaüfer) - foi convidado no fim de 1949 pelo clube de Bremem a proferir uma conferência, que

\footnotetext{
34 «dürfen wir die Entscheidungszonen nicht überspringen wollen.», Martin Heidegger, Gesamtausgabe, Volume 90. Zu Ernst Jünger, éd. par Peter Trawny, Frankfurt am Main, Klostermann, 2004, p. 222.

35 «Weltkriege [...] sind nicht imstande, geschichtlich Geschicke zu entscheiden.», Martin Heidegger, La pauvreté (die Armut). Strasbourg: Presses Universitaires de Strasbourg, 2004, p. 88.
} 
dividirá para a publicação em quatro textos distintos: A coisa, o dispositivo, o perigo, a inflexão (Das Ding, Das Ge-stell, Die Gefahr, Die Kehre). As segundas e terceiras conferências contêm duas passagens terríveis que não serão publicadas senão de maneira póstuma, em 1994, no t. 79 da GA (a primeira passagem havia se tornado pública em 1983 por um ouvinte).

É na segunda conferência, §13, p. 27, que evoca "a fabricação de cadáveres nas câmaras de gás e nos campos de extermínio":

A agricultura é hoje uma indústria da alimentação motorizada, o mesmo em sua essência que a fabricação de cadáveres nas câmaras de gás e nos campos de extermínio (die Fabrikation Von eichen in Gazkammern und Vernichtungslagern), o mesmo que o embargo econômico e a indução de um país a um estado de fome, o mesmo que a fabricação de bombas de hidrogênio ${ }^{36}$.

Câmaras de gás e campos de extermínio não são negados, mas completamente relativizados e reduzidos a um simples dispositivo industrial e técnico, do mesmo modo que a agricultura motorizada, o embargo econômico e o fato de promover a fome de um país, e a fabricação de bombas de hidrogênio. É uma desumanização completa da "solução final". Nem o nome das vítimas: antes de tudo, os judeus, nem o nome dos carrascos: os nacional-socialistas, são pronunciados. Permanece somente um elemento entre outros, tomado em uma enumeração relativizante. A intenção genocida dos nazistas é igualmente apagada: já não se trata de matar um povo inteiro, mas de fabricar industrialmente cadáveres como qualquer outro produto. A expressão "Fabrikation von Leichen", retomada após Heidegger por muitos outros autores dentre dos quais, por exemplo, Giorgio Agamben, corresponde à linguagem que empregava o SS Friedrich Entress e, como o mostraram Raoul Hilberg e François Rastier, procede pois de um 'humor' nazista. Além disso, só um momento do processo de

\footnotetext{
${ }^{36}$ «Ackerbau ist jetzt motorisierte Ernährungsindustrie, im Wesen das Selbe wie die Fabrikation von Leichen in Gaskammern und Vernichtungslagern, das Selbe wie die Blokade und Aushun $\neg$ gerung von Ländern, das Selbe wie die Fabrikation von Wasser $\neg$ stoffbomben» Martin Heidegger, Gesamtausgabe, Volume 79, Bremer und Freiburger Vorträge, éd. por Petra Jaeger, Frankfurt am Main, Klostermann, 1994, 27.
} 
extermínio é retido e isolado, pois Heidegger não diz uma palavra em suas conferências sobre fornos crematórios, fossas comuns, cremação de corpos a céu aberto nos campos de Belzec, Sobibor... Chega assim a inscrever em sua obra um enunciado de uma perversidade calculada e atroz, sem que possa ser acusado no sentido o mais imediato de negacionismo. Entretanto, é bem isso que está presente: silêncio sobre o nome das vítimas e negação de sua humanidade; negação da responsabilidade dos carrascos; o processo técnico bárbaro e terrivelmente primário das câmaras de gás e dos campos de extermínio é imputado ao "dispositivo" planetário do Ge-stell e não aos dirigentes nazistas e a seus executantes.

O segundo texto vai mais longe ainda no revisionismo explícito, para não dizer o negacionismo e na total desumanização das vítimas.

Centenas de milhares morrem em massa. Morrem? Perecem. São abatidos. Morrem? Eles se tornam peças de reserva de um estoque de fabricação de cadáveres. Morrem? São liquidados discretamente nos campos de extermínio. E, sem isso, milhões perecem hoje de fome na China. Morrer, no entanto, significa levar até o termo a morte em sua essência. Poder morrer significa ter a capacidade de se levar até o término. Temos essa capacidade somente quando nossa essência ama a essência da morte. Mas, em meio aos inumeráveis mortos, a essência da morte permanece irreconhecível. A morte não é nem o nada vazio, nem somente a passagem de um ente a um outro. A morte pertence ao Dasein do homem que sobrevive a partir da essência do ser. Assim abriga a essência do ser. A morte é o abrigo o mais alto da verdade do ser, o abrigo que abriga nele o caráter oculto da essência do ser e compõe a salvação de sua essência. Por isso, o homem pode morrer se somente o próprio ser apropria a essência do homem na essência do ser a partir da verdade de sua essência. A morte é o abrigo do ser no poema do mundo. Poder a morte em sua essência significa: poder morrer. Somente aqueles que podem morrer são os mortais no sentido referencial desse termo. Em qualquer lugar encontramos desespero em massa por mortes horrivelmente não mortas - e a essência da morte é dissimulada para o homem. O homem não é ainda o mortal. ${ }^{37 .}$

37 «Hunderttausende sterben in Masse. Sterben sie? Sie kom $\neg$ men um. Sie werden umgelegt. Sterben sie ? Sie werden Bestandstücke eines Bestandes der Fabrikation von 
De novo, nenhum nome, nem das vítimas, nem dos carrascos, mas uma simples cifra: "centenas de milhares" (Hunderttausende), a propósito dos campos de extermínio, que Heidegger compara aos "milhões" (Millionen) de mortos de fome em 1949 na China. No caso dos chineses, o nome das vítimas é explícito. Isso torna tanto mais odioso o silêncio sobre as vítimas judaicas. Ora, se os famintos na China constituem uma realidade terrível, não procedem de uma vontade genocida. A associação heideggeriana é, pois, negacionista em duplo sentido: nega a amplitude real como a vontade genocida da exterminação nazista.

Além disso, não é o dispositivo técnico, o Ge-stell, mas o próprio Heidegger, que, para citá-lo, "instala de antemão uma uniformidade onde tudo se avalia como idêntico", quando relaciona ao "mesmo" as câmaras de gás e a agricultura motorizada. É eximir, ao mesmo tempo, a responsabilidade dos dirigentes nacional-socialistas e eliminar especificidade da destruição dos judeus da Europa. Heidegger evoca nesse momento um processo de extermínio de que não indica nem o lugar, nem a data, nem o nome dos carrascos, nem aqueles das vítimas. Os "campos de extermínio" são reduzidos ao estado de sinais e de sintomas, entre muitos outros, do desencadeamento planetário da técnica. Trata-se de campos de extermínio nacional-socialistas? A palavra Vernichtungslager parece o indicar, mas nada é claro.

Por isso, o negacionismo de Heidegger tem várias dimensões:

Leichen. Sterben sie? Sie werden in Vernichtungslagern unauffällig liquidiert. Und auch ohne Solches - Millionen verelenden jetzt in China durch den Hunger in ein Verenden. Sterben aber heißt, den Tod in sein Wesen austragen. Sterben können heißt, diesen Austrag vermögen. Wir vermögen es nur, wenn unser Wesen das Wesen des Todes mag. Doch inmitten der ungezählten Tode bleibt das Wesen des Todes verstellt. Der Tod ist weder das leere Nichts, noch ist er nur der Übergang von einem Seienden zu einem anderen. Der Tod gehört in das aus dem Wesen des Seyns ereignete Dasein des Menschen. So birgt er das Wesen des Seyns. Der Tod ist das höchste Gebirg der Wahrheit des Seyns selbst, das Gebirg, das in sich die Verborgenheit des Wesens des Seyns birgt und die Bergung seines Wesens versammelt. Darum vermag der Mensch den Tod nur und erst, wenn das Seyn selber aus der Wahrheit seines Wesens das Wesen des Menschen in das Wesen des Seyns vereignet. Der Tod ist das Gebirg des Seyns im Gedicht der Welt. Den Tod in seinem Wesen vermögen, heißt: sterben können. Diejenigen, die sterben können, sind erst die Sterblichen im tragenden Sinn dieses Wortes. Massenhafte Nöte zahlloser, grausig ungestorbener Tode überall - und gleichwohl ist das Wesen des Todes dem Menschen verstellt. Der Mensch ist noch nicht der Sterbliche.» GA 79, 56. 
1. negação da derrota nazista de 1945;

2. suspensão da responsabilidade dos nacional-socialistas para com seus crimes;

3. supressão de toda referência explícita ao genocídio dos judeus por Hitler e

4. utilização retórica de um "questionamento" reiterado destinado a sugerir que as vítimas dos campos de extermínio não são mortos (gestorben) propriamente falando, não são "mortais", pois elas não estão na "guarda do ser". É preciso medir adequadamente tudo o que há de hediondo ao insinuar que as crianças, as mulheres exterminadas pelos nazistas, não puderam morrer (sterben), porque não amavam "a essência da morte". É uma discriminação radical, um racismo ontologizado que persegue as vítimas até na morte.

À qual concepção da morte remete a "necrofilia" heideggeriana? A morte autêntica é concebida, no $§ 53$ de Ser e Tempo, como um "sacrifício de si" (Selbstaufgabe) em benefício "da comunidade, do povo" (der Gemeinschaft, des Volkes, § 74). Ela anuncia a apologia heideggeriana, formulada nos mesmos termos do Mein Kampf, do "sacrifício" (opfer) do indivíduo para a comunidade do povo (Volksgemeinschaft), a exemplo de Alberto-Leo Schlageter, "herói" segundo os nazistas, cujo aniversário da morte será celebrado com tanta ênfase pelo reitor Heidegger ${ }^{38}$. É uma concepção sacrificial da morte, notadamente recusada por Adorno no Jargão da autenticidade.

Mas é preciso ir até a raiz da concepção heideggeriana da morte. Atrás das «mortes horrivelmente não mortas» (grausig ungestorbener Tode) das Conferências de Bremem, encontra-se a concepção heideggeriana «do morrer» (das Sterben), distinguido em Ser e tempo do «perecer» (das Verenden). Essa distinção da língua alemã é quase intraduzível em inglês ou em francês: trata-se com efeito de distinguir o morrer (Sterben), que seria próprio do Dasein, e o fato de perecer (verenden) que se diz de todos os vivos ${ }^{39}$. Em resumo, «morrer se diz do modo de ser na qual o

\footnotetext{
${ }^{38}$ Ver Martin Heidegger, Gesamtausgabe, Volume 16, Reden und andere Zeugnisse eines Lebensweges, éd. por Hermann Heidegger, Frankfurt am Main, Klostermann, 2000, p. 759-760.

${ }^{39}$ Ver Martin Heidegger, Sein und Zeit, § 47, p. 240-241.
} 
Dasein é para sua morte. Por conseguinte, é preciso dizer que o Dasein não perece (verendet) nunca $\rangle^{40}$. Quando se diz que as vítimas dos campos de extermínio são mortos «horrivelmente não mortos» (grausig ungestorben), quando é afirmado que elas não são, propriamente falando, mortais (Sterbliche), Heidegger faz certamente referência ao extermínio em massa, mas as alusões às condições de extermínio não representam senão uma pequena parte do texto. Sobre as quatorze frases do segundo e terceiro parágrafos da citação que fiz, duas frases somente evocam as mortes incontáveis. Incomparavelmente mais desenvolvida se encontra o tema da morte como «abrigo da essência do ser», de sorte que não podem morrer senão aqueles cuja essência é apropriada pelo ser ele mesmo. Isso significa que as vítimas destinadas a serem liquidadas em massa nos campos de extermínio nacional-socialistas não podem propriamente morrer, não são, propriamente falando, mortais, não simplesmente por seu número e pelo caráter coletivo de seu extermínio, mais ainda porque, segundo Heidegger, o ser mesmo não lhes deixa a possibilidade de poder morrer. Como não ver que essa discriminação, que esse «negacionismo ontológico» tenha alguma coisa de revoltante e monstruoso?

Até o momento, os heideggerianos que haviam contestado minha interpretação das Conferências de Bremem, não haviam posto em voga senão as breves alusões ao extermínio de massa, ou haviam contestado minha tradução de mögen por «amar», que é bem contudo um dos sentidos do verbo alemão. A fraqueza de sua crítica se via no que nenhum dentre eles não se arriscava a retomar e a justificar a longa argumentação heideggeriana que nega àqueles, que não estão no abrigo do ser, a possibilidade de morrer. A interpretação deles repousava, portanto, sobre uma rejeição facilmente contestável. Mais recentemente, dois heideggerianos anglosaxões têm dessa vez baseado sua crítica sobre um contrassenso maciço de minha própria interpretação, imputando-me sem razão a tese segundo a qual Heidegger teria afirmado que não teria havido vítimas nos campos de extermínio nazistas ${ }^{41}$ ! É, entretanto, bem manifesto que Heidegger

\footnotetext{
${ }^{40}$ Martin Heidegger, Sein und Zeit, §49, p. 247.

${ }^{41}$ Ver Robert Bernasconi, "Race and Earth in Heidegger's Thinking during the late 1930s", The Southern Journal of Philosophy 48 (Mars 2010), p. 58, e Laurence Paul
} 
não partilha o negacionismo histórico de um Faurisson, visto que fala de centenas de milhares de vítimas, afirma que elas foram liquidadas etc. É bem por essa razão que forjei a expressão «negacionismo ontológico»: é, com efeito, o ser mesmo das vítimas, sua existência como mortais que é posta em causa e não o fato bruto de seu extermínio. Desejamos, portanto, que a leitura desse estudo, ou daquele que havia publicado em inglês, em 2006, e citado na bibliografia de meu livro, possa esclarecer-vos.

Mas retomemos o fio de minha demonstração de conjunto: os textos das Conferências de Bremem sobre o extermínio que evoquei não devem ser isolados do conjunto das publicações de Heidegger após 1945. É preciso igualmente levar em conta seus elogios, dessa vez, perfeitamente explícitos, do movimento nacional-socialista e de sua "singularidade histórica": em 1953, com a edição de A introdução à metafísica, em 1976, com a publicação póstuma da entrevista dada ao Spiegel, ou em 1984, com a publicação, na Gesamtausgabe, do curso intitulado, Der Ister. Não, somos, pois, confrontados somente com propósitos isolados de Heidegger, perturbados e insustentáveis, mas com um "movimento", um projeto, uma estratégia de conjunto do espírito negacionista e nazista no que se diz e no que se cala.

\section{A técnica, o nacional-socialismo e o extermínio}

Falta pôr em evidência um ponto essencial, a saber, que a rejeição heideggeriana da técnica e sua apologia persistente do nacionalsocialismo, após 1945, não são dissociáveis. Com efeito, assim como no parêntese acrescentado, em 1953, quanto na entrevista de 1976, Heidegger liga estreitamente os dois. Na Introdução à metafísica, o

\footnotetext{
Hemming, "Introduction", em: The Movement of Nihilism: Heidegger's Thinking After Nietzsche, éd. por Laurence Paul Hemming, Kostas Amiridis et Bogdan Costea, New York/ London, Continuum, 2011, p. 3-6. Hemming parece não ter de Bremen Lectures senão um conhecimento de segunda mão, pois ele não distingue as duas passagens onde Heidegger fala de campos de extermínio e situa o texto sobre a «mechanized food production» na conferência intitulada The Danger, enquanto que ela se encontra em realidade na conferência intitulada $O$ Dispositivo (ver sua introducão, p. 3 e a nota 11, p. 6). Para uma discussão crítica mais completa das observações de Robert Bernasconi, ver E. Faye, "Subjectivity and Race in Heidegger's Writings”, Philosophy Today 55 (Octobre 2011), p. 268-281.
} 
elogio indigno da "verdade interna e da grandeza" do "movimento" nacional-socialista é comentado em um parêntese que, sabemos hoje, foi acrescentado às provas da edição em 1953: "(isto é, com o encontro da técnica determinada planetariamente e do homem moderno)" ${ }^{\prime 4}$. No SpiegelGespräch de 1976, afirma que o "nacional-socialismo foi bem na direção" (der Nationalsozialismus ist zwar in die Richtung gegangen) de uma "relação satisfatória" (ein zureichendes Verhältnis) do homem à "essência da técnica"43. Ora, em que consistem esse "encontro" e essa "relação satisfatória" realizados, segundo ele, no nacional-socialismo? A referência de 1953 à técnica planetária confunde voluntariamente as pistas, pois não é assim que ele se exprimia quando das vitórias do III Reich. É preciso se referir aqui ao que Heidegger escreve em maio/junho de 1940, no momento em que as divisões blindadas do III Reich invadem a Holanda, a Bélgica e as Ardenhas Francesas. Em seu curso do semestre de verão de 1940, intitulado Der europäische Nihilismus, comenta muito precisamente a derrota da França como sendo aquela de um povo que já não está "à altura da metafísica oriunda de sua própria história" ( $d a \beta$ ein Volk eines Tages der Metaphysik, die aus seiner eigenen Geschichte entsprungen, nicht mehr gewachsen ist) e exalta por contraste a "nova humanidade" vitoriosa nestes termos:

É preciso uma humanidade que seja profundamente conforme à essência fundamental singular da técnica dos Tempos Modernos e à sua verdade metafísica, isto é, que se deixa totalmente dominar pela essência da técnica a fim de poder assim precisamente dirigir e utilizar por si mesma os diferentes processos e possibilidades técnicas ${ }^{44}$.

\footnotetext{
42 «nämlich mit der Begegnung der planetarisch bestimmte Technik und des neuzeitlichen Menschen » Martin Heidegger, Einführung in die Metaphysik, Tübingen, Max Niemeyer Verlag, 1953, p. 152.

43 «zum Wesen der Technik» Martin Heidegger, "Spiegel Gespräch", in Antwort. Martin Heidegger im Gespräch, éd. par Günther Neske et Emil Kettering, Pfullingen, Günther Neske, 1988, p. 105.

${ }^{44}$ «Es bedarf eines Menschentum, das von Grung aus dem einzigartigen Grundwesen der neuzeitlichen Technik und ihrer metaphysischen Wahrheit gemäß ist, d.h. vom Wesen der Technik sich ganz beherrschen läßt, um so gerade selbst die einzelnen technischen Vorgänge und Möglichkeiten zu lenken un zu nützen.» Martin Heidegger, Nietzsche II, Pfullingen, Günther Neske, 1961, p. 165-166.
} 
Mais explícita, ainda, a conclusão do curso, suprimida em 1961, pois excessivamente comprometedora, mas restabelecida um quarto de século mais tarde, em 1986, com a publicação do volume 48 da Gesamtausgabe, engrandece a "a motorização total - isto é, aqui, radicalmente fundamental da Wehrmacht" como constituindo para ele "um ato metafísico, de que não se deve duvidar e que supera em profundidade a supressão da "filosofia"45. Os propósitos de Heidegger em uma carta a Elfride, do mesmo ano de 1940, vão no mesmo sentido. Ele fala de uma "profissão de fé absoluta na lógica interna da tecnização absoluta da guerra", na qual "o ser isolado desaparece enquanto indivíduo"46.

Assim, "a relação satisfatória" à técnica estabelecida sob o nacionalsocialismo corresponde à motorização da Wehrmacht e à tecnização incondicionada da guerra concebidas em termos próximos a Jünger, como um caldeirão de uma nova humanidade. Mais isso não é tudo, falta mostrar o mais terrível. A implicação, com efeito, não é somente militar, trata-se na verdade de uma coisa diferente de uma simples revanche a ter sobre o que Heidegger nomeia, em suas observações sobre Jünger da mesma época, as "potências do oeste" (die Westmächte) ${ }^{47}$. Ao ler as conferências de Bremem, descobre-se, com efeito, que ele confere ao nacional-socialismo uma outra 'especificidade' quanto a sua relação à "técnica". Já não se trata da motorização da Wehrmacht engrandecida na primavera de 1940, mas dos campos de extermínio e das câmaras de gás.

Ora, se prestamos atenção ao fato de que Heidegger é, ao mesmo tempo, o autor de seus enunciados de suas conferências de Bremem publicadas somente em 1994, após sua morte, e das duas apologias do nacional-socialismo em sua relação com a técnica, publicadas em 1953 e 1976, tomaremos consciência da monstruosidade de sua posição: sua apologia recobre, com efeito, a dupla especificidade do nacional-socialismo

\footnotetext{
${ }^{45}$ Martin Heidegger, Gesamtausgabe Volum 48, Nietzsche: Der Europäische Nihilismus éd. par Petra Jaeger, Frankfurt am Main, Klostermann, 1986, p. 333.

${ }^{46}$ «eine unbedingte Verschreibung an die innere Gesetzlichkeit der unbedingten Technisierung des Krieges. Der Einzelen verschwindet als Individuum. » Martin Heidegger à Elfride, Mein liebes Seelchen!, 18 mai 1940, p. 210.

${ }^{47}$ Martin Heidegger, Gesamtausgabe, Volume 90, Zu Ernst Jünger, éd. par Peter Trawny, Frankfurt am Main, Klostermann, 2004, p. 221.
} 
quanto à técnica: motorização da Wehrmacht e câmaras de gás nos campos de extermínio como coroamento da seleção racial. Se Heidegger defende a relação estabelecida pelo nacional-socialismo com a técnica, é porque uma e outra são estimadas portadoras de uma "verdade interna", de uma "grandeza", e reveladoras de uma direção julgada satisfatória.

Como pode acontecer que quase ninguém tenha até hoje tomado consciência dessa posição monstruosa? Os comentadores de Heidegger têm costume de parafrasear isoladamente seus diferentes textos e de descontextualizá-los mais ou menos completamente. Ora, nem a hermenêutica, nem a desconstrução, nem a escola de Gadamer, nem a de Derrida, que permanecem uma e outra excessivamente na superfície dos textos, não podem aqui ser de grande ajuda. A procura da verdade exige uma síntese em profundidade do pensamento. É preciso, ao mesmo tempo, uma introspecção, uma síntese e uma recontextualização dos escritos. Por isso, a história e a filologia devem aqui acompanhar o trabalho do filósofo.

Tomemos o curso redigido para o semestre de inverno de 1941 - 1942 e intitulado A metafísica de Nietzsche (Nietzsches Metaphysik). Esse curso é geralmente considerado como uma simples apresentação da filosofia de Nietzsche. Penso, ao contrário, ter suficientemente mostrado, não somente nesta conferência, mas, sobretudo em meu livro, que os cursos e as conferências de Heidegger representam a cada vez uma tomada de posição sobre a atualidade (das Heutige). À qual efetividade da história corresponde esse curso? Ele aí expõe de novo o tema de extermínio (Vernichtung) já reivindicado em 1933 - 1934. No entanto, seu discurso sobre o extermínio é, dessa vez, explicitamente vinculado à legitimação histórico-ontológica do que ele nomeia "o princípio da instituição de uma seleção racial" (der Prinzip der Einrichtung einer Rassenzüchtung), julgado por ele "metafisicamente necessário" (metaphysisch notwendig) a partir do momento em que o ser é concebido como subjetividade.

Acrescentamos que Heidegger tomou cuidado de precisar no fim de sua introdução que "a apresentação do pensamento de Nietzsche e sua interpretação são elaboradas juntas ao ponto de se interpenetrar" ${ }^{\text {"48. }}$. Não são

\footnotetext{
${ }^{48}$ Martin Heidegger, Gesamtausgabe, Volume 50, 1. Nietzsches Metaphysik. 2. Einleitung in die Philosophie - Denken und Dichten, éd. par Petra Jaeger, Frankfurt am Main,
} 
somente os termos da filosofia que Heidegger utiliza como Deckname, mas também os nomes dos filósofos e de certos poetas: Heráclito, Hölderlin ou aqui Nietzsche, embora, neste último caso, as coisas sejam mais complexas: tanto o apelo ao extermínio do inimigo interior não é de Heráclito, quanto às citações de Nietzsche sobre o "material humano" ou sobre "o pensamento aniquilador" que ele evoca são já por elas mesmas inquietantes. No entanto, elas se transformam mais ainda e recebem historicamente um sentido novo no contexto do extermínio nazista em que Heidegger as profere.

Os apologistas de Heidegger tentaram sustentar que sua evocação da seleção racial constituía em realidade uma crítica à seleção racial. Basta, entretanto, ler a tonalidade toda positiva das páginas onde Heidegger expôs a "necessidade metafísica" do "princípio da instituição de uma seleção racial" para ver que esse não é o caso. Está com efeito em questão o "gigantesco próprio ao grande estilo" (das Riesenhafte des großen Stils) e a "plenitude do ser próprio ao que é simples" (die eigene Wesens fülle jenes Einfachen) ${ }^{49}$. Nas páginas que seguem imediatamente, fala-se - em termos que lembram suas teses do curso de primavera de 1940, mas aplicadas, dessa vez, já não à vitória militar, mas à exterminação racial - em moldar uma nova humanidade incondicionada, que se encarregue da dominação da terra e que execute a seleção racial para passar os seres humanos pelo crivo até o ponto de não retorno (die Menschen aussiebt...zu Entschlüssen) ${ }^{50}$. Donde sua apologia do extermínio que "assegura contra o afluxo de tudo o que condiciona a decadência" ${ }^{51}$. Já não é, como na primavera de 1940, a vitória militar do III Reich sobre a França que é doravante histórica e ontologicamente legitimada, mas bem a escolha da "solução final" e o extermínio dos judeus que começou no Fronte do Leste desde o verão de 1941.

Não posso evocar senão algumas curtas passagens desse curso sobre Nietzsche. A leitura atenta dos cursos dos anos seguintes me leva a pensar que o estudo aprofundado dos cursos dos anos de 1942 - 1944

Klostermann, 1990, p. 8-9.

${ }^{49}$ Ibid., 57-58; trad. fr. 2005, p. 67-68.

${ }^{50}$ Ibid., 59-60; trad.. fr. p. 70-71.

${ }^{51}$ «Das Vernichten sichert gegen den Andrang aller Bedingungen des Niederganges.» Ibid., 70 ; trad.. fr., p. 82 . 
- particularmente aquele que se refere ao hino de Hölderlin Der Ister e aqueles intitulados Heráclito e Parmênides - confirmaria e agravaria essas análises $^{52}$. No entanto, com o que é publicado na Gesamtausgabe, incrementado pelos seminários inéditos que parcialmente editei, podemos já saber muito a esse respeito se nos atermos a sondar em profundidade o caminho traçado por esse conjunto. Hoje é bem claro que o nacionalsocialismo de Heidegger não é alguma coisa do passado. É uma realidade que quis projetar no futuro, programando ele mesmo não somente o plano, mas igualmente, em suas grandes linhas, a ordem de publicações dos volumes da Gesamtausgabe. É assim que, após os cursos sobre Nietzsche, publicados durante os anos de 1980, e as conferências de Bremem de 1949, publicadas em 1994, os textos os mais explicitamente hitlerianos, racistas e portadores de uma vontade de exterminação são publicados em 1998, 2000 e 2001, como para acompanhar a passagem para o terceiro milênio. Podemos ver claro hoje no modo pelo qual Heidegger quis se servir dos termos da filosofia e do nome de certos filósofos e poetas para difundir e legitimar planetariamente tais enunciados. É, pois, hoje que podemos medir toda a necessidade do trabalho de verdade do filósofo, que somente pode nos permitir a resistir à tentativa heideggeriana de legitimar o nacionalsocialismo utilizando a linguagem mesma da filosofia.

Data de registro: $16 / 10 / 2011$

Data de aceite: 16/11/2011

\footnotetext{
${ }^{52}$ Pesquisas complementares são ainda indispensáveis. Seria necessário ainda que os pesquisadores tivessem livre acesso a todos os arquivos, por isso lancei um apelo para a abertura dos Arquivos Heidegger, que foi publicado pelo jornal Le Monde, em 5 de janeiro de 2006, p. 22, reeditado sob a forma de uma petição pela revista alemã Theologie. Geschichte (2006): aps.sulb.uni-saarland.de/theologie.geschichte/inhalt/2006/16.html, e igualmente posto na rede mundial de computadores em: http://archives-heidegger.hermeneute.com.
} 